\title{
Roberto F. Giusti y la Revista "Nosotros"
}

\author{
(A PROPÓSITO DE UNA ENTREVISTA \\ A ROBERTO F. GIUSTI)
}

I

NVITADo por el diario La Prensa para hablar en su prestigiosa tribuna del Instituto Popular de Conferencias, visité, en julio del corriente año, la ciudad de Buenos Aires, capital de mi patria, la Argentina. Tuve ocasión de encontrarme allí, de nuevo, con mis queridos maestros y viejos y admirados amigos: Ricardo Rojas, a cuyo sepelio debí asistir dolorido; Arturo Capdevila, quien me hizo el honor de presidir el acto de La Prensa en el que hablé sobre "Realidad y poesía en los Estados Unidos de Norteamérica"; Francisco Romero, con quien mantuve una cordial entrevista en el Instituto de Filosofía de la Universidad de Buenos Aires, del cual es actualmente su director, y muchos otros cuya sola mención me honrarían y llenarían de satisfacción. Pero quiero referirme especialmente a mi encuentro con Roberto F. Giusti, no sólo por ser hoy el decano de la crítica argentina (por su longevidad, después de la muerte de Ricardo Rojas, y por la magnitud de su obra), sino por la circunstancia de celebrarse este año varios acontecimientos trascendentales en su vida y en la vida cultural argentina, tales como: a) el cumplir 70 años de edad; b) el celebrar sus "Bodas de Oro" con la profesión literaria; c) el cumplirse cincuenta años de la aparición de la revista Nosotros, de la que fue uno de sus fundadores. 
Roberto F. Giusti, su vida y su obra.

En su retiro hogareño de Martínez, provincia de Buenos Aires, o en la redacción del diario La Prensa (suplemento literario de los domingos), o en el Instituto de Literatura Iberoamericana de la Facultad de Filosofía y Letras de la Universidad de Buenos Aires, o en el Colegio Libre de Estudios Superiores, o en la Academia Argentina de Letras, se puede uno encontrar con Roberto F. Giusti. Y en todo momento podemos hallar al hombre de mediana estatura, pero robusto, de cabello un tanto canoso y con mechón un poco a "coup de vent", como en los deportistas latinos, con extensa nariz aguileña y abanicadas orejas, con ojos adolescentes que traducen amor paternal y cordialidad amistosa, con manos inquietas que acompañan infatigablemente su apasionado hablar, y con esa boca de niño oculto tras el gesto o la palabra, que parece triturar entre los dientes y ahogar en su saliva cualquier altivez humana o las inevitables amarguras de la vida. Sí, porque Giusti es todo modestia y bondad, lleva consigo, en su rostro y en su modo habitual de ser, la imagen ideal de los cruzados y de todos los abanderados de las grandes causas. Su vida y su obra así nos lo dicen, y lo he confirmado en mis pláticas de este año. Me invitó a pronunciar una conferencia en el Colegio Libre de Estudios Superiores sobre Baldomero Santín Cano, cuya muerte, ocurrida meses atrás, se mencionaba respetuosamente, al par que evocaba amistades nobles y recuerdos insustituibles del ilustre embajador colombiano en la Argentina. De Giusti recibí la palabra de estímúlo que sólo pueden dar los grandes maestros a los jóvenes que necesitan orientación y ayuda, como siempre supo hacerlo también otro maestro en la Argentina y en toda América, el Dr. Pedro Henríquez Ure$\tilde{n} a$, nunca lo suficientemente llorado, alabado y reconocido. $Y$ a Giusti deben dos generaciones de argentinos su aliento constante para escribir y publicar y su generoso ayuda personal e intelectual, en la revista Nosotros y en numerosos ensayos de crítica sensata y bien intencionada. Francisco Romero, hoy otro indiscutible guía de las juventudes argentinas en tan difícil momento de la vida de aquel país, no hace mucho decía a propósito de la publicación de los Ensayos de Roberto Giusti coleccionados por sus amigos y admiradores: 
En muchos casos la obra y la personalidad del escritor son separables; el poeta, el novelista, algunos otros tipos de creadores intelectuales, pueden quedar para el lector al margen de sus producciones y hasta reclamar que sólo se atiende a ellas. Pero en otros casos la obra y el autor componen unidad, y aquélla, pese a bastarse a sí misma y a reposar en sus propios méritos, gana en significación y cobra su relieve pleno cuando se la contempla respaldada por el hombre que la realizó. En otras ocasiones, y aun en alguna para mí memorable - mi última disertación en el Instituto Popular de Conferencias [de La Prensa], en 1950, no sin alusión a las circunstancias de entonces y poco antes de que la tiranía [se refiere a la de Perón, de la que fueron víctimas tanto Giusti como Romero] impidiera el funcionamiento de esa meritoria institución-, he examinado este tema de las relaciones entre el creador y su creación, con referencia a la filosofia. Mientras que en la obra de pura ficción, como señalé antes, y también en la producción científica, por su objetividad patente que acarrea una fuerte dosis de impersonalidad y la pone a cubierto de los desvíos más manifiestos, la creación habla por sí, y en medida notable se convierte en criterio para juzgar a quien la produjo; hay otros géneros de la labor cultural donde de continuo la personalidad del agente debe integrarse con su producción para atribuir a ésta su justo alcance. Ocurre así siempre que la obra comporta compromiso y responsabilidad íntima, esto es, cuando la individualidad del autor, su densidad humana, su entereza y veracidad pesan en ella por comportar actitudes y juicios que pueden ser falseados por conveniencias o temores.

De este orden es la faena del filósofo, cuyas intuiciones $y$ convicciones son materia adecuada por su delicada naturaleza para desvirtuarse y torcerse hacia donde sopla el viento, si no las mantiene en la línea recta una austera voluntad de verdad. $Y$ también entra en este grupo la actividad del crítico, acaso más expuesta a la autotergiversación, porque no sólo inciden en ella las solicitaciones externas sino también un constante reclamo interior -muy explicable por otra parte aunque tienda a falsificar sus dictámenes - a la lenidad o la excesiva tolerancia, a la ordenación de valores según la escala de los afectos personales, el deseo de "quedar bien con todos", motivos operantes en todas partes y más en ambientes reducidos como el nuestro, en el cual todos nos conocemos y con frecuencia nos encontramos. Nótese que no cuento aquí los casos de injusticia manifiesta, los extremos culpables del 
favor o del disfavor por razones no intelectuales, sino que me atengo a lo que suele ser admitido y disculpado. Para nadie son requisitos tan indispensables la honradez, la buena fe, el valor de exponer con sinceridad y franqueza el propio punto de vista, y la resolución de plan. tearse previamente cada juicio como un caso de conciencia, como para el crítico, sobre todo para el crítico de literatura y de arte, materias donde la apreciación puede descarriarse por innumerables motivos.

Con la enumeración de estos requisitos tenemos ya algunos elementos para la semblanza de Giusti, porque en él concurren ejemplarmente. La semblanza completa me guardaré mucho de intentarla en estas apuntaciones, porque forzosamente se disminuiría un asunto necesitado de mucho más espacio que el permitido ahora. Baste recordar, a los fines de esta nota, la incansable labor crítica cumplida por él desde sus páginas iniciales, su visible y tenaz empeño de clarificación en el confuso campo de nuestras letras, la prudente mezcla de incitación generosa y de rigor discriminativo, y por encima de todo el afán de ser siempre veraz y justiciero. A estas cualidades, entre intelectuales y morales, o dicho de otro modo, definidoras de un ejercicio de la inteligencia saturado de sentido ético, ha de agregarse, y también de destacarse, porque no siempre se percibe, un amor a nuestra literatura que le ha llevado a consagrarle horas y esfuerzos, cuando acaso otros temas requerían su atención y el eludirlo significaba sacrificio. En la ternura militante y exigente, en la vigilancia severa y cordial con que ha seguido y comentado durante cincuenta años los desiguales episodios de nuestra vida literaria, hay algo así como la voluntaria aceptación de un deber $y$, desde luego, el desempeño de un magisterio y aun de una magistratura. Que la obligación era ardua, escasa en compensaciones y necesitada de calidades poco comunes, lo prueba el hecho de que el papel de crítico "profesional" de nuestras letras durante un largo período ha estado casi exclusivamente a su cargo.

Separar netamente la labor crítica de Giusti contenida en notas, artículos y ensayos, de otras formas de su actividad, sería introducir cortes artificiales en una ocupación muy vasta y compleja, cotidiana durante muchos años, toda ella gobernada por el mismo levantado propósito, el de servir los intereses universales de la inteligencia y los de la cultura argentina. Al crítico propiamente dicho se han sumado en Giusti, en un designio semejante, el profesor sapiente y escrupuloso, animador de vocaciones juveniles, nunca olvidado por quienes tuvie- 
ron la suerte de ser sus alumnos, y el consejero amistoso y veraz en la conversación y en esas cartas a escritores noveles o maduros que nunca adoptaron el tono convencional de la mera cortesía o del fácil elogio encubridor de la real indiferencia. Muchas otras cosas habría que recordar para situar en su lugar dentro de nuestra cultura de este medio siglo al varón que supo erigir en la revista Nosotros la más vasta sede de nuestras letras, y que al prodigarse en toda empresa de desinterés y bien público supo también tomar dignamente su puesto en la defensa de la civilidad argentina. ${ }^{1}$

Sin duda hemos abusado de la cita, pero el ensayo de Romero podría ser transcripto íntegramente, porque nadie nos ha dado hasta ahora una visión sintética más clara y justa del autor y la obra que estamos comentando. Por lo demás, sus palabras, además de venir de quien vienen, se hallan confirmadas en expresas confesiones del propio Giusti y nos eximen de cualquier interpretación subjetiva. Nos dice en sus Ensayos:

He procurado conciliar la ordenación cronológica con la diversidad de direcciones de mi curiosidad intelectual; también he querido que detrás de mis razones sobre autores y libros se percibiera que el ensayista nunca ha sido indiferente a los problemas morales y sociales que todo juicio crítico serio entraña. Dicho con otras palabras: que no he sido un literato puro, solamente atento a la letra de los libros, sordo a la voz de los hombres que les forman a aquéllos el ámbito espiritual. Que sin ser propiamente grave, ni menos solemne, he aspirado a que me juzgaran serio. Seriedad no incompatible con la sonrisa y aun con la risa franca que hice estallar en algunas de mis páginas polémicas, o acerbamente combativas.?

Queda así presentada su personalidad y definida su actitud de crítico, cuyas características fundamentales expondremos en otra oportunidad. Ahora sólo nos proponemos dar los datos de mayor interés de su vida y las referencias principales a sus obras, para que sirvan de introducción a las palabras con que

I Francisco Romero, "Bodas de oro con la producción literaria" (La Prensa, Buenos Aires, 18 de mayo de 1956, sección segunda).

2 Roberto F. Giusti, Ensayos (Buenos Aires: Edición Homenaje de los Amigos, 1955), p. 8. 
Giusti reseña la vida de la revista Nosotros con todas sus vicisitudes.

Roberto Fernando Giusti nació en Lucca, Italia, el 10 de marzo de 1887. A los 8 años de edad, en 1895, se incorporó a la vida argentina, en donde hizo todos sus estudios, hasta graduarse de Doctor en Filosofía y Letras en la Universidad de Buenos Aires, en 1912. Ese mismo año inició la publicación de sus libros de crítica literaria, con Nuestros poetas jóvenes, revista crítica de la poesía argentina de entonces, que publicó bajo el sello editorial de Nosotros y que resulta ser hoy obra de consulta imprescindible por no haber sido superada todavía. Ya en 1907 había fundado con Alfredo Bianchi la revista Nosotros, en donde realmente se inició como investigador y crítico y cuya dirección compartió durante 34 años, en sus dos épocas: 1907-1934 (81 tomos) y 1936-1943 (23 tomos). Desde entonces su vida fue repartida entre la profesión literaria, el periodísmo y la docencia, con períodos de militancia política en el Partido Socialista, que lo llevó a ocupar posiciones como la de concejal de la ciudad de Buenos Aires durante dos períodos (1921-1926) y la de diputado nacional, en representación del partido Socialista Independiente, por el Distrito Federal (la ciudad de Buenos Aires) durante los períodos de 1928-1930 y 1932-1934. Fue también vicepresidente de la Cámara de Diputados en el período de 1933-1934. De 1923 a 1953 fue catedrático de Literatura Castellana de la Edad Media y de Composición Literaria en el Instituto Nacional del Profesorado Secundario de Buenos Aires, en donde compartió la educación de la juventud estudiosa argentina con maestros como Pedro Henríquez Ureña, Amado Alonso y Francisco Romero. Además fue profesor de literatura y gramática castellana en los colegios nacionales "Mariano Moreno" y "Manuel Belgrano" y profesor de latín en el Instituto del Profesorado Secundario "Mariano Acosta". En 1943 fue destituido de sus cátedras, como tantos otros profesores liberales y democráticos, por la dictadura vigente. Caída ésta, en 1955, fue llamado por las autoridades de la Universidad de Buenos Aires para dirigir el Instituto de Literatura Iberoamericana y para desempeñar la cátedra respectiva en la Facultad de Filosofía y Letras. En estas funciones se encuentra en la actualidad, has- 
ta que se haga cargo de las mismas el profesor que fue elegido titular en los recientes concursos que presidió el mismo Giusti, o sea, el Dr. Enrique Anderson Imbert. En la fecha es columnista de $L a$ Nación, prestigioso diario fundado por Bartolomé Mitre, y colaborador del suplementeo literario dominical del diario La Prensa. Desde 1936 es miembro de la Academia Argentina de Letras, y desde 1949, correspondiente de la Academia Nacional de Artes y Letras de La Habana, Cuba. Forma parte actualmente de la Comisión Directiva del Colegio Libre de Estudios Superiores, del cual es miembro fundador. En 1924 integró el Consejo Directivo de la Facultad de Filosofía y Letras de la Universidad de Buenos Aires. Presidió durante dos períodos (1934-1937) la Sociedad Argentina de Escritores, de la que también es miembro fundador y a la que representó ante la Comisión Nacional de Cultura. En 1934, el Secretario de Estado de los Estados Unidos de Norteamérica, Cordell Hull, le hizo una invitación especial para que visitara E.U. como huésped de honor del Departamento de Estado. No pudo concurrir por impedimentos personales.

Su obra, como hemos dicho, empieza a publicarse en libros desde 1912, con Nuestros poetas jóvenes (Buenos Aires: Edición. Nosotros, 1912) y registra hasta la fecha los siguientes títulos: Crítica y polémica, en cuatro series: Primera serie, 1917; Segunda serie, 1924; Tercera serie, 1927; Cuarta Serie, 1930. Por las dos primeras series recibió el premio de la Municipalidad de Buenos Aires (primer premio, sección prosa) en 1925; Enrique Federico Amiel en su "Diario Intimo" (Buenos Aires: Edición Nosotros, 1919) ; Florencio Sánchez (Buenos Aires: Agencia. Sud-Americana de Libros, 1920); Mis muñecos [cuentos y fantasías] (Buenos Aires: Cooperativa Editorial, 1923) ; Literatura y vida (Buenos Aires; Edición Nosotros, 1939) ; Siglos, Escuelas, Autores (Buenos Aires: Edición Problemas, 1946); Momentos y aspectos de la cultura argentina (Buenos Aires: Editorial Raigal, 1954); Ensayos: Edición Homenaje de los Amigos, 1955); $A$ las cataratas [cuentos] (Buenos Aires: Ediciones Luar, 1956) ; Poetas de América (Buenos Aires: Editorial Losada [Biblioteca Contemporánea], 1946). En 1917 publicó el diálogo de Leopordi Parini o de la Gloria, en traducción propia, 
con prólogo y notas. Desde hace veinte años circulan en la Argentina y diversos países de Hispanoamérica sus manuales para la enseñanza del idioma y la literatura española, argentina e hispanoamericana, editados por la Casa Estrada y Compañía de Buenos Aires, algunos de los cuales llegan ya a veinte ediciones. Tales son: Nuestro idioma; Curso de Gramática Castellana (3 tomos); Lecciones de Literatura Española y Antologí; Lecciones de Literatura Hispanoamericana y Antología; Lecciones de Literatura Española, Argentina e Hispanoamericana. Muchos de sus ensayos, reseñas y notas se hallan dispersos en diarios y revistas y son hoy de difícil lectura. Pero el autor considera (en carta que nos ha enviado) que ellos no agregarían nada a los que han sido reunidos en sus libros.

Sobre la obra de Roberto F. Giusti existe ya una bibliografía que prestigian firmas como las de Roberto Brenes Mesén, Fidelino de Figueiredo, Andrés Iduarte, Francisco Contreras, Hernán Díaz Arrieta ("Alone"), Francisco Romero, Alberto Zum Felde, Luis Emilio Soto, Manuel Pedro González, José María Monner Sans y Raúl Montero Bustamante. Precisamente este último, actual presidente de la Academia Nacional de Letras del Uruguay, decía no hace mucho del Guisti ensayista:

En cuanto a Ensayos, he estado sumergido en su lectura en los días de malestar que suelen depararme mis males. :Qué incomparable compañía para las horas de silencio y de vigilia! iCuántos recuerdos ha traído a mi memoria y cuánto me ha enseñado! [...] El maestro es figura insigne de las letras hispanoamericanas; el hombre es espejo de luchadores por el ideal, que está constituido, sobre todo, por las cosas del espíritu; el amigo está definido por ese hermoso volumen, que es testimonio de la amistad y de la admiración, $\mathrm{y}$ es también monumento de la justicia erigido a quien no ha cesado durante medio siglo de ofrecer a los lectores el sereno "curso de sus pensamientos y sentimientos"."

Y uno de los más jóvenes y promisores críticos argentinos

3 "Sobre los Ensayos de Roberto F. Giusti", en Cursos y Conferencias. Revista del Colegio Libre de Estudios Superiores. Buenos Aires. Año XXVI, Vol. L, Núm. 276, marzo de 1957, págs. 91-92. 
actuales, Juan Carlos Ghiano, lo caracteriza con estas palabras de discipulado:

No resulta ociosa la lista de publicaciones de Giusti porque todas ellas se animan con un doble fervor, que está en la raíz de sus preocupaciones americanas; por una parte el interés en exaltar nuestros valores, situando el juicio literario en las proporciones sociales y éticas que han sostenido la persistencia de los maestros de América; por la otra la vocación docente, que se afirma sobre la cordialidad de la persuasión. Ambas calidades prolongan esa riqueza espiritual que aprovecharon sus discipulos y aprecian quienes conocen los motivos de sus diálogos y de su correspondencia. Más de un novel escritor quisquilloso se ha dejado conducir por el nítido apoyo de su juicio, que sabe resguardar los valores destacables aun en la página más expuesta a modificaciones; muchos criticos e historiadores de las letras argentinas (oculten su influencia o la destaquen con orgullo) han aprendido en sus estudios que penetran los temas, iluminándolos en sus aspectos esenciales, sin ocultar los posibles reparos, a la vez que los sitúan en el conjunto de las creaciones humanas. ${ }^{4}$

Giusti surgió en la vida cultural argentina en momentos en que, ya pasada la avalancha optimista de los "profesores de idealismo", típicos representantes de las élites burguesas que entendían la literatura como una de las tantas dinámicas del "despotismo ilustrado", el arte dejó de ser patrimonio de minorías selectas y salió a buscar la vida en los estrados del pueblo. El inmigrante italiano encontró en la urbe cosmopolita todas las formas de esa estética que Fechner quería von unten (desde abajo) y concibió su militancia un poco a la ma-

4 Juan Carlos Ghiano, "Homenaje a Roberto F. Giusti", en Crademos Americanos, México. Año XIV, Núm. 4, julio-agosto de 1955, p. 293. Ghiano hace en esta nota una reseña de la labor de Giusti, con datos de interés, que no hemos repetido por razones obvias. Véase también: Salomón Wapnir, La crítica literaria argentina (Buenos Aires: Ediciones Acanto, 1956), pág. 25 y sigs.; Alberto Zum Felde, Indice critico de la literatura bispanoamericana. El ensayo y la critica (México: Editorial Guarania, 1954), págs. 406-407; y Manuel Pedro González, Estudios sobre Literaturas Hispanoamericanas. Glosas y Semblanzas (México: Edición "Cuadernos Americanos", 1951), págs. 208-216; véase también de Ghiano "Homenaje a Nosotros y a Giusti" en Ficción, Buenos Aires, No. 9, septiembre-octubre de 1957, pp. 93-100. 
nera de cómo la había enseñado Taine: el arte como lo más aristocrático y lo más popular, porque dice las más altas cosas para una mayor cantidad de gentes. Con el auge del socialismo y las huestes bien preparadas del positivismo que había convertido en ciencia el maestro Ingenieros, amasó en sus garras de pionero y soñador, entre Aníbal Ponce y Alejandro Korn (inada menos!) todos los utensilios de la crítica impresionista, determinista o retórico-pasatista que se demoraba por aquellos tiempos y lugares. $Y$ así dibujó huellas y prodigó instrumentos de lucha hasta levantar los andamios por donde los gustadores del quehacer literario anduvieron paseándose hasta la llegada del martinfierrismo y la aparición de la crítica filológica-estilística que vino después con Amado Alonso y la Revista de Filología Hispínica. No sabemos todavía cuál de las dos tendencias será la más perdurable. Por de pronto, Giusti da siempre en la vida, mientras que la otra crítica da en el arte, la literatura, y más de una vez sólo en la gramática y la retórica. En el medio parece estar el bando nacionalista, que hace investigación, historia y crítica, partiendo de una materia siempre apetecible: lo nacional, nativo, regionalista y folklórico. $Y$ cuando no la encuentra la inventa y prodiga en cuadros ideales, simbólicos, elocuentes, patrióticos y patrioteros. En países jóvenes, sin una tradición que determine corrientes de ideas por sí mismas, la crítica literaria tampoco puede darse como simple ejemplaridad de métodos y trabajo académico. Por eso, la obra de Giusti está hoy más que nunca en el fondo y detrás de las búsquedas de los jóvenes más afanosos por dar un sentido a la realidad en que viven y un valor efectivo a las obras de que se nutren intelectual y artísticamente. En Buenos Aires parece que están un poco cansados de las paradojas inescrutables, estilo borgiano, (claro que sin Borges), o de los recuentos de sensaciones y senestesias al modo de ciertas prácticas malamente estilísticas. Queremos a Giusti - le oí decir a unos jóvenes-, porque nos llega, nos dice algo, nos hace sentir y comprender. ¿Y qué más que eso puede pretender la crítica literaria? 
La revista Nosotros y sus vicisitudes

¿Quién no conoce en E. U. a la revista Nosotros? En este país, en donde tanto se hace por los estudios hispanoamericanos - y por toda clase de estudios - no hay profesor universitario, más o menos "scholar", que no maneje sus páginas, no hay universidad de cierto prestigio que no guarde en sus anaqueles los 104 tomos de la colección completa. Madaline W. Nichols y Lucía Burk Kinnaird han clasificado pacientemente sus temas y han compuesto sendos índices bibliográficos de sus artículos de crítica literaria y educación. En los congresos de profesores universitarios y escritores que a cada año se celebran en distintas partes del país, hemos visto ponencias sobre la revista Nosotros o sobre Roberto F. Giusti y la crítica hispanoamericana. Por tanto, no parece necesario que hablemos detenidamente de la prestigiosa publicación. Allí están autores y ensayos que nos dicen de su orientación, sus descubrimientos, su cuadro de ideas, sus valores literarios. Pero será muy útil que también se conozca en los E. U. la historia de la revista contada por uno de sus fundadores. Esta historia, que Giusti nos ha confiado para que demos a ella el destino que creamos conveniente, ha sido publicada muy fragmentariamente por los diarios de la Argentina. Por eso creemos necesario publicarla completa, tal como Giusti la redactó para ser leída en el acto de clausura de la exposición de revistas argentinas patrocinada por la Comisión Nacional de Cultura y que se llevó a cabo en el mes de mayo de 1957. Nos dice Giusti: "entendí que, cofundador y director sobreviviente de la revista Nosotros, bien podía, sin ser tachado de presumido, hablar en el cincuentenario de la fundación de una revista literaria cuya vida de un tercio largo de siglo fue la más prolongada de que hay memoria en la historia del pensamiento argentino y aún hispanoamericano, de una empresa intelectual que juntó las ambiciones, los sueños, la labor y los frutos de, por lo menos, dos generaciones". $\mathrm{Y}$ así comienza la historia. Dejamos la palabra al protagonista esencial.

AlFredo A. RogGiano, State University of Iowa, Iowa City, Iowa 


\section{TEXTO DE ROBERTO F. GIUSTI}

Nosotros no quiere decir Bianchi y Giusti, como algún chistoso malévolo pudo pensarlo y acaso decirlo en los corrillos literarios del tiempo de la fundación. La genérica denominación abarcaba la promoción juvenil que en sus páginas se resolvía a expresarse en el segundo lustro del siglo. Eso escribí en la "Presentación" del primer número, correspondiente a agosto de 1907. No se me ocultaba entonces que el título podía parecer algo petulante, pero "Nosotros - decía- es una revista de jóvenes, y como tal se presenta armada de aquel ardimiento que una esperanza todavía no decepcionada presupone". El título lo sugirió Alberto Gerchunoff en el saloncillo de Emilio Becher en la redacción de La Nación y en un círculo en cuyo seno en cierto modo nació la revista. Lo reclamó amistosamente por suyo Roberto Payró, avisando que había publicado años antes en las columnas del mismo diario el primer capítulo de una novela de ese título, probablemente recordado por Gerchunoff. Consistió la transacción en reproducir en el primer número aquel capítulo de la novela de ambiciones zolianas dejada trunca en sus comienzos, precedido por el artículo que ese año de 1896 había publicado sobre la misma Rubén Darío, quien le decía a su amigo: "Intentas encerrar en tu libro a Buenos Aires". A Bianchi y a mí también nos bullía en la subconsciencia la idea de encerrar en nuestra revista Buenos Aires, $y$, está de más decirlo, la entera Argentina. Pero si se mira la cubierta del primer número, se verá que un gallardo atleta con la cabeza ceñida de laureles y empuñando en la izquierda una trompeta heroica, sostiene en la derecha nada menos que el globo terráqueo con el hemisferio de las tres Américas vuelto hacia el contemplador. No recuerdo quién lo dibujó o de dónde lo tomamos, pero indudablemente, si ambiciosa la alegoría que ilustró varios años la cubierta, mostraba cabalmente que no podía ser interpretada como el retrato fotográfico o literario de los dos directores. Ella entrañaba el propósito, cumplido a través de los años y declarado en dicha "Presentación", de vincular en las páginas de la revista a los escritores de América Latina; he dicho latina porque desde el 
segundo número también tuvimos una sección de letras brasileñas a cargo de Juan Más y Pi. Cuando festejamos con un banquete el segundo aniversario de la fundación, ya habían colaborado en Nosotros, a nuestra solicitud, una o más veces, los cubanos Márquez Sterling, Manuel Pichardo y Arturo R. de Carricarte, los uruguayos Samuel Blixen, Raúl Monero Bustamante, Carlos Vaz Ferreira y José Enrique Rodó, el mejicano Amado Nervo, el peruano José Santos Chocano, el nicaragüense Rubén Darío, los colombianos Max Grillo, Antonio Gómez Restrepo, Samuel López, Manuel Cervera y Guillermo Valencia, los venezolanos Rufino Blanco Fombona y Felipe Valderrama, y además escritores y periodistas nacidos en otras tierras de América residentes en Buenos Aires, los uruguayos Florencio Sánchez, Horacio Quiroga, Víctor Arreguine y Otto Miguel Cione, los bolivianos Arturo Pinto Escalier y Luis Ipiña, el paraguayo Eloy Fariña Núñez y el colombiano Pedro Sonderéguer. Por algunos como por muchos de estos nombres ya ilustres o que lo serían, ustedes han visto que las primeras mieses no habían sido malas. Reputo superfluo encarecer las que siguieron durante más de treinta años en un suelo cada vez más fértil en amistades continentales, pues debe tenerse en cuenta que cuando salimos a la calle aún los lectores argentinos mejor informados conocían muy imprecisamente lo que se publicaba en otras partes de América. Max Grillo, reputado literato colombiano, reconociendo que Nosotros era desde el año de su aparición "lugar de cita de los escritores sudamericanos donde se dan a conocer unos a otros", afirmaba: "Ya es tiempo que la Argentina se dé cuenta de que está llamada a asumir la dirección de las demás naciones de origen hispano"; y agregaba: "yo sueño en verla a la cabeza de Sudamérica con legítima hegemonía. En la realización de este ideal las publicaciones como Nosotros llenan un hermoso deber".

La misma conducta seguimos con los escritores españoles. En el segundo número, junto a la sección Letras Francesas que inauguraba Atilio Chiáppori, iniciaba Gerchunoff una de Letras Españolas. Unamuno nos honró con una conceptuosa carta al recibir ese número. 
Una historia anecdótica del nacimiento de Nosotros la escribí hace treinta años justo en el número con que conmemoramos el vigésimo aniversario, volumen, lo digo con justicia, realmente extraordinario por la calidad de los colaboradores y la extensión y mérito de las colaboraciones. No he de repetirla, por poco conocida que sea, aunque también ande en libro. ${ }^{1}$ La iniciativa correspondió totalmente a Alfredo Bianchi, con quien yo había trabado amistad en la Facultad de Filosofía y Letras el año 1904. Bianchi era un revistero nato, desvelado, incorregible, porfiado, vicio que había contraído en el umbral del siglo y siendo todavía alumno del Colegio Nacional, cuando administró con el después brillante periodista y humorista Enrique M. Ruas, en 1900, la pequeña revista Rinconete y Cortadillo, y después, antes de conocerme a mí, el año siguiente, fundó por su sola cuenta y riesgo, aunque no mal acompañado, Preludios, que pasó de los cuarenta números, y de 1904 a 1906 fue, como secretario de redacción y factotum, el alma de La Gaceta. A Nosotros yo aporté, junto con mi precoz vocación de plumífero, una buena dosis de escepticismo. Se incubó la revista contemporáneamente en en el ya dicho saloncito de Becher y en las mesas del café de Los Inmortales, dos zonas más o menos bohemias, recelosas la una de la otra, si no en guerra declarada. Puesto entre las encontradas ojerizas, nosotros los reconciliamos en las páginas impresas y al cabo en la vida. Porque nuestro propósito fue unir; no, dividir. Unir también las viejas firmas consagradas con las nuevas ya conocidas y con aquéllas de los que surgían entonces o habrían de surgir. No practicamos por deporte el estridentismo literario y el lenguaje ásperamente agresivo, los cuales encubren a menudo impaciencias que, cuando dan a luz, paren, o despreciables conformismos o insospe. chados autoritarismos, ello también en política. Tampoco practicamos el dócil conformismo literario, aunque no el sistemático desconocimiento de los valores, grandes o pequeños, que tenía el país. La que entre los años 1920 y 1930 se llamó a sí misma la "nueva generación", careció de esa ecuanimidad.

1 Critica y Polémica, cuarta serie, Buenos Aires, 1930. 
Gracias a esa política literaria, rarísimos escritores ar. gentinos vivientes rehusaron en los primeros años, y menos en los sucesivos, colaborar en nuestras páginas. Prácticamente llegamos, en un momento, en que la heredad estaba vacía. Sólo vegetaba en ella la Revista de Derecho, Historia y Letras, fundada y dirigida por el Dr. Estanislao Zeballos, publicación indefinida, aunque meritoria, de escasa difusión en los ambientes literarios. Nosotros heredaba a algunos colaboradores del extinto Mercurio de América, empezando por su director, el poeta Eugenio Díaz Romero, el cual atendía entonces la sección "Letras Hispanoamericanas" en el Mercure de France, y casi toda la juvenil falange de Ideas, la revista fundada por Manuel Gálvez y Ricardo Olivera en 1903: Ricardo Rojas, Emilio Becher, Atilio Chiáppori, Emilio Ortiz Grognet, Alberto Gerchunoff, Carlos Octavio Bunge, Antonio Monteavaro. Les incorporamos el grupo de Más y Pi, Evaristo Carriego y Marcelo del Mazo, en general el del café, hoy legendario, de los Inmortales, a la vez que tendíamos la vista en todas direcciones en procura de reclutas y veteranos. Con esta política literaria de puertas abiertas, Nosotros alcanzó a ser, en su orden, la expresión más característica de su tiempo, órgano de varias generaciones que trabajaron en común. Por supuesto, fuimos hijos del tiempo. En aquella crónica de veinte años de vida, a la cual antes me he referido, examiné esa política literaria a la luz del ambiente espiritual de la anteguerra. Piénsese que en 1907, cuando apareció Nosotros, la actividad intelectual porteña distaba muchísimo de tener la riqueza y variedad actuales. Ya se había atenuado mucho el entusiasmo literario suscitado por Rubén Darío. Ningua tendencia se señalaba con rasgos acentuados en ese momento de disolución de la escuela simbolista y de total dispersión en la poesía, hecho del cual es espejo mi libro Nuestros poetas jóvenes, de 1911. Otro tanto dígase con respecto a Buenos Aires, y, por consiguiente, a la República entera, de las corrientes filosóficas y las doctrinas políticas, las cuales fueron adquiriendo rasgos nuevos y definidos en vísperas de la guerra, al doblar el siglo el primer decenio. Pues conviene recordar que Nosotros no fue una revista estrictamente literaria. Respetando distancias, quiso ser lo que eran en Francia entonces autorizadas pu- 
blicaciones, como la Revue des Deux Mondes, la Revue de Paris, el Mercure de France, y otras: de letras, arte, filosofía, historia y ciencias sociales. No encontramos vanguardias literarias cruelmente agresivas; apenas sí francotiradores más o menos irreverentes, como yo también lo fui, con Leopoldo Lugones y algún otro; y así Nosotros pudo crecer y cobrar fuerzas y prestigio en un ambiente muy necesitado de fraternidad literaria, como lo prueba la insistencia con que lo calificábamos en toda ocasión propicia, de beocio, fenicio o cartaginés, que el nombre variaba según el gusto.

Cuando en los lustros posteriores a la primera conflagración mundial se encendieron en el mundo llameantes fervores ideológicos de redención humana, Nosotros no fue indiferente a ellos, sin dejar por eso de ser un campo abierto a todas las opiniones; y cuando estallaron en Buenos Aires los cohetes literarios dichos genéricamente vanguardistas, pirotecnia en que se cruzaba el futurismo italiano con el ultraísmo español y con algunos ismos franceses, Nosotros, en la doble condición de campo neutral donde todas las tendencias podían expresarse y de punching-ball para los muchachos peleadores que necesitaban hacer gimnasia, no fue en ningún momento hostil a los nuevos. No quisimos, eso no, ser revista de círculo. Fracasaron cualesquiera intentos hechos para embanderarnos. Nosotros fue de todos. Lo fue particularmente de los jóvenes, de los recién llegados, sin creernos obligados a publicar, por supuesto, las primeras planas de los escolares aplicados. En nuestras páginas publicó Borges, en diciembre de 1921, la primera definición del ultraísmo hecha en el país. Avisó la revista al darle cabida en sus páginas que con ese estudio iniciaba una serie sobre las escuelas de vanguardia. "Queremos hacer conocer - avisaba la redacción- los principios estéticos de las nuevas escuelas literarias y artísticas. El solo hecho de exponer a todas -antagónicas entre sí, con frecuencia-, prueba nuestra neutralidad en la batalla". Y preguntaba: “ ¿Será verdad que comenzamos a envejecer?" El año siguiente publicaba la revista a cinco poetas que se decían ultraístas, una especie de antología de la nueva poesía, antecesora de la de Vignale y César Tiempo. Eran Borges, F. Piñero, Norah Lange, la uruguaya Clotilde Luisi, Helena Martínez, Roberto 
Ortelli, Guillermo Juan y González Lanuza, La primera revista que manifiestamente fue órgano de la llamada "nueva sensibilidad", tuvo vida por inspiración de Alfredo Bianchi. Él reunió una noche a los fundadores, de cuyo grupo saldría pronto por cariocinesis Proa, otra revista de vanguardia, para aconsejarles la conveniencia de que los jóvenes de la nueva generación literaria tuvieran un órgano propio, en el cual pudieran exponer libremente sus opiniones sin chocar en las mismas páginas con las ideas y los prejuicios de hombres de otras generaciones. Con estos sentimientos amplios, generosos, entendía Bianchi la política literaria. Yo aconsejé entregar en propiedad unos pliegos de cada número de Nosotros a la voluntad exclusiva de los fundadores de Inicial, para que dirigiesen una sección de vanguardia con entera libertad, y así se hizo. En Nosotros, en 1923, Bianchi y Julio Noé, quien me sustituyó unos tres años en la dirección, desempeñándose con su reconocida cultura, gran tino y aliento innovador, después de haber abierto las páginas de la revista a la nueva generación, les preguntaron cuáles eran sus amores y sus odios literarios y, por cierto, esos mozos no se hicieron rogar para despacharse a su libérrimo antojo. Incluso algunos de esos jóvenes escritores dilucidaron sus cuestiones de competencia y de derecho sobre esto y aquello en las páginas de Nosotros.

Quisimos agrupar, pues, y no dividir. Había sus motivos. En 1927 pude escribir, aludiendo a las piedritas que nos tiraban al tejado los camorristas de Martín Fierro, periódico de batalla literaria, en su tercero avatar: "No nos hagamos ilusiones. Los que nos jactamos de intelectuales, en América formamos todavía un círculo demasiado reducido, estrechado por la indiferencia cuando no por la hostilidad del ambiente, para que nos peleemos a muerte sobre si hemos de decir galopar o beber horizontes".

Pero el tejado era firme. Donosamente lo describió Fer. nández Moreno en el lindo romance que en 1932 nos dedicó a los directores:

Que contra escuela y capilla, indiferencia $\mathrm{y}$ desaire, ha habido siempre un tejado, 
un torreón de diamantes, con un Nosotros, corazón de un estandarte.

Y permítasele a mi pequeño orgullo descender del tejado para continuar un poco más con el poeta:

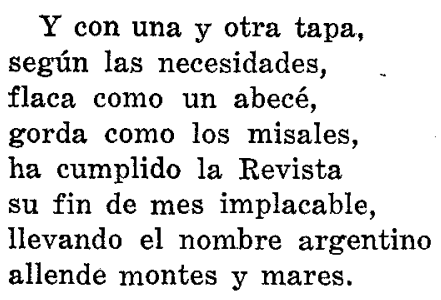

Aún en aquęllos breves años en que Nosotros concitó la animadversión de Martín Fierro, nuestra revista siguió practicando la indeclinable hospitalidad que fue su norma, incluso con los de ese grupo, la mayoría de los cuales colaboraban todavía o habían colaborado o colaborarían en las denostadas páginas. Solamente contraatacamos cuando fue menester, en poquísimos casos de legítima defensa, con rápidas dentelladas, para las que confieso haber afilado los colmillos cuanto me fue posible. Pero esta es historia anecdótica, de intrascendentes escaramuzas literarias, sobre la que no debo volver. Debo sí recordar, a fin de que se medite sobre las mudanzas humanas, aunque guardándome de reeditar hoy los reproches de antaño, que Evar Méndez (en el siglo, Evaristo González), convertido, en la dirección de Martín Fierro, no en sus versos, en feroz vanguardista, se había estrenado en el primer número de Nosotros con una liviana imitación de Rubén Darío, un "tríptico a la manera de Watteau", según decía el subtítulo, muy a lo Rey Sol. Era el hallazgo que tenían reservado a nuestra revista Ricardo Rojas y Atilio Chiáppori, descubridores del joven poeta mendocino. Nosotros teníamos nuestro hallazgo: el de Enrique Banchs, de quien publicamos en el primer número tres sonetos, incluidos ese mismo año en su primer libro, Las Barcas. En el tercer número llegó el turno de Evaristo Carriego con "Cosas de Andresillo", composición incorporada después a Misas herejes. 
La historia, si larga, de toda institución, empresa, publicación periodística, pasa, naturalmente, por distintas etapas, sufre rachas de buena y mala fortuna. Nosotros, empresa de dos muchachos que no tenían ciertas noches cómo pagarse un café, no pudo constituir una excepción. Haré gracia al lector de referirle los aprietos financieros por que pasamos, los obstáculos materiales que hubo que vencer-empezando por la indiferencia de los libreros y la informalidad de muchos agentes-, las vanidades, incomprensiones, envidias, que nos salieron al paso, los sectarismos políticos y literarios de todo color que pretendieron aprisionarnos. A este último propósito, iqué lucha! Nosotros quiso ser siempre una tribuna libre. Ni escrúpulos, ni obligaciones, ni consideraciones de ninguna naturaleza le hicieron traicionar el programa que se impusieron los dos directores cuando la fundaron. Más de una vez debimos advertirlo: "Si el tono de sus páginas sorprende e inquieta, opóngase razón a razón, sentimiento a sentimiento, ideal a ideal, a ese tono otro tono. Eso es vida: la unanimidad y acuerdo rebañegos son la muerte". Por eso fue también tribuna polémica.

Nunca nadamos en la abundancia. Tuvimos días de respiro y días de angustia, agravados por la escasez de papel y otras escaseces que trajo la primera guerra mundial. El año del centenario de la revolución de Mayo suspendimos la publicación; a los pocos meses, el tesón de Bianchi, el imperioso, desesperado anhelo que lo subyugaba de tener "su" revista, volvió a ponerla, a principios de 1911, en los escaparates de las librerías. En 1912, ante una crisis semejante, resolvimos convertirla en sociedad cooperativa, contando con el patrocinio ilustre del poeta Rafael Obligado, el cual accedió a presidirla. Con tal transformación administrativa y la reducción del formato, nació ese año con el número 43 la Nosotros más recordada y difundida, elegantemente impresa en excelente papel por la Compañía Sudamericana de Billetes de Banco, hasta el 1918, y desde entonces hasta el último número, por la bien equipada imprenta de Antonio Mercatalli y sus hijos, Mario y Francisco. A fines de 1934, ya disuelta desde hacía tiempo la cooperativa, nos vimos forzados a decir "basta". Ochenta y un tomos nutridos formaban la colección que por esos mismos 
días había merecido un preciso catálogo analítico, hecho por las profesoras Madaline W. Nichols y Lucía Burk Kinnaird, subsidiado por la Universidad de Stanford y el Dominican College y publicado en distintas revistas especializadas de los Estados Unidos, catálogo que es hoy una rareza bibliográfica. Fui yo el que escribí en la Navidad de 1934 la larga carta de la suicida a los colaboradores y amigos, con que encabezamos el número 300. En ella recordaba que una existencia tan dilatada, de veintiocho años, a partir del primer número (en ese momento no sospechaba que se prolongaría ocho años más), no había sido alcanzada por ninguna publicación de la índole de Nosotros. "Muchas semejantes - escribí- hemos visto nacer, con fraternal simpatía, y con tristeza perecer, mientras en esta casa nos manteníamos firmes en medio de innumerables dificultades de todo orden. Veintiocho años son un largo espacio de tiempo para cualquier empresa humana; lo son para los regímenes políticos, para los ciclos literarios, para las evoluciones morales y sociales. En veintiocho años cabe toda la historia que va desde la toma de la Bastilla hasta la caída de Napoleón; en menos tiempo se hizo la constrastada unidad de Italia y de Alemania; no mucho más ha durado el largo imperio del último Hohenzollern; el mismo lapso corrió entre Caseros y la capitalización de Buenos Aires, entre la ascensión de Mitre a la presidencia y la revolución del Noventa. No es pueril hacerlo presente: son unos pocos ejemplos que ofrecemos a la reflexión del culto lector, a modo de unidades de medida, para que nos absuelva si ahora escribimos aquí: Queda cerrado el ciclo de Nosotros. Debemos insistir sobre esto, cuando hay quienes nos reprochan afectuosamente: iMorir! : Darse por vencidos! No es posible. ¿Acaso no pueden o no saben proseguir? Tal vez en otras manos más capaces... Sí, quizá en otras manos, lo reconocemos, las cosas andarían de diferente modo; pero primero concédasenos la premisa del razonamiento: Nosotros vivió veintiocho años, y el caso es único en el país. Quince meses vivió La Abeja Argentina, el periódico mensual que publicaba la Sociedad Literaria en tiempos de Rivadavia; ocho años la Revista de Buenos Aires, de Vicente Quesada y Navarro Viola; seis la Revista del Río de la Plata, de Lamas, López y Gutiérrez; cuatro la Nueva Revista de Bue- 
nos Aires, de los Quesada, Vicente y Héctor; seis, entre sus dos épocas, la Revista Argentina, de Estrada y Goyena; nueve, la Revista Nacional, de Carranza y Vega Belgrano; dos, La Biblioteca, de Groussac; veintitrés, la de Derecho, Historia y Letras, de Zeballos; del mismo modo han durado pocos años, tres, dos, uno, raramente más, todas las revistas literarias de intención seria, grandes o pequeñas, que se han publicado después de aquéllas, antes de la aparición de Nosotros o contemporáneamente: la Revista de América, de Darío y Jaimes Freyre; el Mercurio de América, de Díaz Romero; Ideas, de Gálvez y Olivera; $E l$ Sol e Ideas y Figuras, de Ghiraldo; Renacimiento, de Florencio César González y Más y Pi; Atlántida, de David Peña; Ideas, del Ateneo de Estudiantes Universitarios; Hebe, de Morales y Novillo Quiroga; Pallas, de Chiáppori; Helios, de Conde Montero; Atenea, de Arrieta; Nuestra América, de Stefanini; Revista Nacional, de Jurado e Irazusta ; Biblios, de Rafael Barrios; Azul, de Bartolomé Ronco; Var loraciones, de Alejandro Korn y su grupo; Sagitario, de Amaya, Julio V. González y Sánchez Viamonte; Síntesis, de Martín Noel; y, por cierto, las de los nuevos y novísimos, Inicial, Proa, Prisma, Martín Fierro, Letras, Megófano. Lo mismo puede decirse de los demás países de América. Las mencionadas y otras iguales que lamentamos no recordar en este momento [téngase presente que esto fue escrito hace veintitrés años y que, además, incluye alguna sensible omisión] han sido nobles esfuerzos, de los cuales quedará memoria en la historia de nuestra cultura. Reclamamos entre ellos un lugar $-\mathrm{y}$ no el último-para Nosotros".

Preguntábamos más adelante: “¿Quién ha dicho que las instituciones sean eternas? ¿Y por qué habría de serlo una revista literaria? Pero la cuestión es más honda: ¿no estará en tela de juicio, no ya la existencia de una determinada revista, sino la de todo un género de publicaciones, las cuales tuvieron auge, y algunas vida gloriosa, en el siglo XIX y a principios del presente, $y$ hoy van siendo desalojadas, si no tienen un peculiar carácter de especialización, por otros medios informativos? El fenómeno se produce en mayor o menor grado también en Europa, pues el hecho de que sean centenarias algunas revistas de allá, tal la gloriosa Revue des Deux Mondes, 
aparte de producirse en un país de superior densidad cultural. como es Francia, guardadora celosa de sus tradiciones, se explica con suma sencillez, porque aquella revista nació precisa y oportunamente y floreció largos decenios en la época que habría de presenciar el magnífico desarrollo de las publicaciones de su mismo género. En Europa recientemente-decíamoshan desaparecido algunas ilustres. Otras, aun viviendo todavía, se ve que ya han hecho su tiempo. Nosotros lo reconoce así para su caso. Este tipo de publicación amplia, ecléctica, acogedora, en cuyas páginas alternan por colaboración espontánea la prosa con el verso, colección de ensayos y artículos de diferente extensión sobre las más variadas cuestiones concernientes a la cultura general, presentada en formato de libro $\mathrm{y}$, por consiguiente, cara y de circulación limitada, ya no es solicitada como lo fue un tiempo. Nosotros supo responder dignamente a ese llamado de la opinión culta argentina, creando en torno suyo un rico y fecundo movimiento intelectual y dando nombre, por el consenso de muchos críticos ilustrados, a una generación y a una época de nuestra cultura, cuyo valor y cuyos frutos, mejor que los contemporáneos, juzgará el porvenir. Son trescientos números, son ochenta y un tomos, son decenas de miles de páginas que han circulado en casi medio millón de ejemplares. Páginas de distinto valor, expresión de la cultura argentina en sus manifestaciones nobles y destacadas; por tanto, desiguales como ella y con sus naturales imperfecciones. En ellas se leen las inquietudes, las esperanzas, los anhelos de este cuarto de siglo [decíamos entonces, cuando la segunda inmensa conflagración mundial sólo comenzaba a vislumbrarse] bárbaramente sacudido, removido y quebrado por la guerra y la revolución; es de creer que esas palabras, que hoy a algunos pueden parecer muertas, despertarán ecos de simpatía en la inteligencia y en el corazón de los lectores e investigadores de mañana".

Como entonces me atreví a hablar, según se ha oído, de una generación de Nosotros, y en otro pasaje de esta crónica he hablado de, por lo menos, dos generaciones, me detendré brevemente sobre el particular, ya tratado por otros. ¿Hubo tal generación literaria? A mi vanidad personal le convendría 
contestar que sí; mi juicio objetivo propone otra respuesta. Cuanto he dicho prueba que no hubo una generación de Nosotros, por la razón sencillísima que en nuestra redacción y en nuestras páginas convergieron desde el primer momento hombres de edades, tendencias y gustos muy diferentes; que hubo, sí, un clima de Nosotros, un benéfico clima de labor hecha en común, camaradería, tolerancia, buena fe, recíproca consideración, aborrecimiento de la retórica y la agresividad gratuita, y esto es muy importante, de total desinterés material, empezando por los directores.

En 1932, el número extraordinario con que celebró la revista sus bodas de plata, propuso la cuestión a escritores de diferentes edades. Fue una encuesta instructiva, una contribución no desdeñable a la historia de la cultura argentina de este siglo, en la cual Nosotros está presente en la mayoría de las respuestas; sin embargo, en lo esencial vino a probar la conclusión que yo he ofrecido: el encuentro y la conciliación en sus páginas, desde los comienzos, de hombres de edad y procedencia intelectual y literaria distintas.

He visto morir otras muchas revistas, grandes y chicas, desde aquella fecha. No sabría hacer el catálogo de todas. Básteme recordar a însula, interesante publicación trimestral que fundó y dirigió la escritora Renata Donghi de Halperín, y a Realidad, expresión de un calificado grupo de escritores y profesores, cuya cabeza dirigente era Francisco Romero, y, que, sin embargo, sólo vivió de enero de 1947 a diciembre de 1949 , si bien financiada por una culta escritora. Sospecho los sacrificios que exige a Victoria Ocampo la edición de Sur, la notable revista, distinta y distante de Nosotros, cuyo primer número saludamos en enero de 1931; y los que le reclama, sin duda, al novelista Juan Goyanarte, el sostenimiento de Ficción, la revista-libro bimestral- de reciente aparición (adviértase la definición significativa). Estas son evidencias, entre tantas otras, que confirman aquel diagnóstico y pronóstico mío antiguo. Sin embargo, venciendo el descorazonamiento, aún no nos dimos por vencidos. Nos despedíamos en aquella carta confiando en que tal vez no sería para siempre; pensábamos que la revista podría renacer posiblemente renovada $y$ 
transformada, pero siempre al servicio de la inteligencia, no al de la distraída frivolidad. $Y$ fue así. Llegó la tercera etapa. El año 1935, Bianchi no se estuvo quieto y resignado, por más que yo, mefistofélico, le silbaba mi escepticismo. Después de no aceptar varias proposiciones que se nos hicieron de financiar la revista, entre ellas la del entonces Intendente $\mathrm{Mu}$ nicipal, doctor Mariano de Vedia y Mitre, a quien todavía estoy agradecido por su generoso ofrecimiento, encontramos, con la intervención del nunca olvidado crítico, colaborador y amigo Juan Torrendell, un modo decoroso de volverla a editar con la ayuda absolutamente personal y desinteresada de don Rafael Vehils. Conste que Nosotros nunca aceptó atarse a gobiernos y empresas, servir intereses oficiales o particulares. Libre nació, libre murió. Unos pocos años recibió muy limitados subsidios concedidos por el Congreso de la Nación, los que, por su origen popular, no trabaron en ninguna ocasión nuestra libertad de pensar ni pesaron sobre ésta. Así, en marzo de 1936, iniciamos la tercera etapa, aquélla que llamamos con propiedad segunda época, pues no había habido discontinuidad temporal entre las dos etapas anteriores. De 1907 a 1912 fue el fervor juvenil, la búsqueda y el descubrimiento. Eran los años en que Bianchi iba con su libreta por calles y cafés a la caza de suscriptores, contra mi reconvención, la cual sonaba poco menos así: "Nosotros es una revista, una institución seria y ya considerada; tú y yo, los directores, somos humildes tertulianos de corrillo bohemio. No debes asociar en la mente de nadie, anotando suscriptores, dos imágenes dispares. Al hacerlo, disminuyes la idea que debe tenerse de la revista. Bianchi, Giusti son una cosa. Nosotros es otra". Pero él no me escuchaba y quizá tuviera razón. Nuestros abnegados administradores, el primero en el tiempo, Alfredo Costa Rubert, el segundo, Francisco Olbasis, lo confirmaban en ella. La segunda etapa fue de afirmación, de vida plena. La tercera, la llamada segunda época (veintitrés tomos, 93 números) no me atrevo a decir que superó a la anterior, pero ciertamente no le fue inferior. Fue lo mismo y otra cosa. Remozamos la cubierta y la elegante tipografía, agilizamos el contenido, recuperamos a los amigos de la víspera, volvieron 
muchos desertores y en ningún instante pudo decirse que olimos al moho de las cosas viejas. Muy al contrario. Cuando en el número-aniversario del año 27 historié los veinte transcurridos, burlándome un poco de nuestros bullangueros contradictores de la entonces llamada "nueva generación" (iy qué pronto envejecen las nuevas generaciones!) les dije: "Pero, amigos, ¿contra qué y contra quiénes pelean ustedes? Al oír sus gritos el transeúnte creerá que o franquean ustedes esa muralla de Nosotros, que cierra el paso, hosca e inaccesible, a las gallardas huestes novecentistas y la arrasan y siembran sobre sus ruinas la sal de la maldición, o todo un mundo nuevo irá a estrellarse contra ella, abatido y deshecho. Creerá que dentro de esa Bastilla se encierra un pasado tal de oprobio y vergüenza, se maquinan asechanzas tales contra el novísimo descubrimiento de la metáfora, que el duelo no puede ser sino a muerte. Lástima que la realidad sea menos dramática, y no se preste a tan bonitos efectos de contraste. Lo único que se nos puede achacar, a mucho orgullo nuestro, es que no nos hayamos vestido a la última moda. Ahora se lleva mucho la inicial minúscula, los versitos asmáticos sin puntuación y el dibujito faraónico: habernos nombrado nosotros y no Nosotros y ya tendríamos bastantes pecados redimidos".

Debo confesarlo, y lo hago sin rubor: nosotros con minúscula se titularon en cambiantes vivos colores los números de la segunda época y fui yo el trascendental innovador.

Ahorro detalles sobre el desarrollo de esta última etapa, todavía vive en la memoria de muchos. El 16 de mayo de 1939, Bianchi era herido por una hemiplejía. Desde entonces el peso de la revista cargó sobre mis hombros y el de nuestro leal secretario y amigo Oscar Bietti, fino crítico. Después de una nueva recaída, de la cual pareció restablecerse a medias, lo mismo que de la primera, mi grande amigo y compañero falleció el 23 de noviembre de 1942. Su muerte fue, lo digo sin exagerar, un duelo de las letras argentinas. Sus exequias y el número especial en que lo conmemoramos son el testimonio de que no he dicho una frase vulgar. En octubre de 1943, el gobierno de facto del general Ramírez me destituía de mis cátedras por el horrendo delito de haber pedido, junto con un 
centenar de otros firmantes, entre ellos eminentes profesores, "democracia efectiva y solidaridad americana". Entonces vi claramente los días inciertos que se nos venían encima, y descorazonado, contando con el asentimiento de Bietti, cerré la revista y liquidé sus efectos, con ayuda de nuestro fiel administrador Daniel Rodolico. No creo haber tomado una decisión equivocada. Habríamos desaparecido de cualquier otro modo, quizá más peligroso, no digo menos honroso. Hice más: cerré definitivamente Nosotros sin una sola palabra de explicación. ¿Para qué?

Una razón práctica, ajena al desaliento moral y a las consideraciones políticas, concurrió a inducirme a cerrar las puertas de Nosotros. No he empleado una imagen común. He dicho las puertas. Porque una revista literaria es o debe ser algo más que varios pliegos encerrados entre dos tapas. Por escogido que sea el material literario, en él no se agota la revista. A ésta deben llegarle en forma viva las ideas y sentimientos de un grupo, de un círculo, de una promoción, de una generación; los directores deben estar en contacto personal con los colaboradores, recibir de ellos sugestiones, aconsejarse con ellos, poner en relación a unos con otros, acicatearlos por medio de la emulación. La redacción ha de ser una tertulia. Eso fue Nosotros en sus mejores tiempos por la acción de Bianchi, infatigable descubridor de talentos y estimulador de vocaciones. Enfermo él, muerto él, yo no podía imitarlo. No soy un misántropo, los que me conocen lo saben, ni soy hosco, ni desabrido, pero carezco de las posibilidades materiales y de las aptitudes psicológicas que necesitaría para ser centro permanente de una tertulia literaria renovada continuamente a través de los años. Bianchi hizo más. Desde los días del almorzáculo del restaurante Ferrari, evocado por mí en unas memorias nostálgicas, la acción de Nosotros se prolongó en comidas alegres y en banquetes serios pero no aburridos, de mantel largo, de los cuales muchos tuvieron justificada resonancia. Agasajábamos a los escritores extranjeros - iquién los recuerda a todos?- Blasco Ibáñez, Valle Inclán, Gómez Carrillo, Ortega y Gasset, Amado Nervo, Urbina, Eugenio D'Ors, Armando Donoso, Sanín Cano, González Martínez, Benavente, Vasconcelos, 
Alfonso Reyes, Enrique Díez Canedo, y a los argentinos en cuanto publicaban un libro, obtenían un premio, emprendían un viaje o regresaban de él: básteme recordar los magnos banquetes ofrecidos a Rojas y a Groussac. También celebrábamos los aniversarios de la revista. En los que señalaron fechas memorables, los diez, los veinte, los veinticinco años de vida, la casa era echada por la ventana. Además, ordinariamente largos años nos reuníamos en divertidas cenas de camaradería, como fueran las mensuales del restaurante Génova, animados por el ingenio travieso de Ingenieros, cenas que también piden un ameno cronista. Todo ello era vida que bullía en torno de Nosotros y que yo, muerto Bianchi, sólo podía comunicarle a la revista, muy apagada. Súmense los diversos factores expuestos y compréndase cómo Nosotros murió en su hora.

Quedan los ciento cuatro tomos, ofreciéndoles a los lectores de hoy y a los de mañana una rica y variada crónica de la evolución del pensamiento argentino en relación con el universal a lo largo de treinta y siete años.

No sé cuál impresión producirá su lectura en los amigos de curiosear el pasado en páginas que todavía no han amarillecido. Sé que en todas las bibliografías literarias especiales Nosotros figura con contribuciones útiles; que los números extraordinarios dedicados a Florencio Sánchez, a Darío, a Rodó, a Carlos Octavio Bunge, a Guido Spano, a Nervo, a Obligado, a Ángel de Estrada y Joaquín González, a Ingenieros, a Payró, a Groussac, a Lugones, a Bianchi, son repertorios de no escaso valor biográfico y crítico a juicio de los entendidos; que bibliófilos y libreros andan a la caza de las casi inhallables colecciones, solicitadas por los mejores centros extranjeros de estudios, sobre todo de los Estados Unidos; sin embargo, esto no es lo que más interesa a mi corazón, porque puede no ser otra cosa que afanes de bibliófilo, curiosidad erudita, historia disecada y ciencia de catálogo. Me interesa, en cambio, saber si algún lector joven, hojeando esas decenas de miles de páginas, siente en algún instante desaprisionarse de ellas un hálito siquiera de la vida que recogieron en su hora. Vida hecha de vigilias meditativas, trabajosas pesquisas, nobles inspiraciones poéticas, amores, odios, admiraciones, devociones, negaciones, acaso flaquezas y aun miserias, toda la vida que se 
agitó en torno de los dos directores, estrechándolos, acometiéndolos, halagándolos, solicitándolos, entusiasmándolos, comprometiéndolos y robando muchas horas a su descanso y a su propia labor de escritores, sacrificada a la publicidad de la ajena.

ROBERTO F. GIUSTI, Universidad de Buenos Aires, Argentina 